\title{
Redes sociales e instituciones culturales: teoría patrimonial, comunicación y algunas rupturas
}

\author{
Candela González Sánchez | periodista especializada en comunicación cultural \\ URL de la contribución <www.iaph.es/revistaph/index.php/revistaph/article/view/4847>
}

La producción académica en el ámbito de la comunicación y el patrimonio es aún escasa si cometemos el error, inevitable, de comparar con otras disciplinas (conservación, legislación, intervención, etc.). En un debate como el propuesto, centrado en las redes sociales, que cuentan con dos décadas de existencia ${ }^{1}$, se hace más necesario, si cabe, la revisión del corpus teórico y nos planteamos realizar una aproximación al tema a partir del estudio de la presencia de la comunicación en la teoría cultural y patrimonial, entendida esta en un sentido amplio. ¿Qué tratamiento que se ha dado a la comunicación en los textos patrimoniales y/o culturales que han marcado hitos (conceptuales, legales, etc.) en lo que hemos llamado la teoría patrimonial? Queremos saber cómo se ha abordado la comunicación desde el patrimonio, qué función se le ha asignado, cómo se entiende qué puede aportar, cuáles son sus carencias y cómo se relaciona con el surgimiento y devenir de la revolución tecnología y, más concretamente, las redes sociales.

Por ello, repasamos algunos hitos en el tiempo:

\section{La opinión pública presente en la Carta de Atenas (1931)}

La Carta de Atenas (1931) es el primer documento internacional que recoge los principios de la conservación y restauración. Con más de nueve décadas, muchas de sus ideas permanecen vigentes y han inspirado la teoría patrimonial actual, como es el caso de las aportaciones de Gustavo Giovannoni sobre el concepto de ambiente (entorno). En su articulado, plantea algunas claves para el estudio de la comunicación y el patrimonio, como la importancia de que la legislación patrimonial esté al tanto de la opinión de la comunidad, al tiempo que alude a la necesidad de difundir los conocimientos y resulta- dos de la investigación y práctica patrimonial (artículos 6.b y 8.d).

\section{La difusión en la primera ley de patrimonio de España (1933)}

Por su parte, la primera ley de patrimonio en el Estado, la Ley del Patrimonio Artístico Nacional (1933), a diferencia de sus antecesoras (Ley de Excavaciones Arqueológicas de 1911, Ley de Monumentos Arquitectónicos-Artísticos de 1915 y Decreto-Ley de 9 de agosto de 1926, sobre la Protección, Conservación y Acrecentamiento de la Riqueza Artística) recoge por primera vez el concepto de difusión en relación con el patrimonio, al incluir una sección de difusión de la cultura artística en la Junta Superior del Tesoro Artístico.

\section{Interpretación del patrimonio (1957)}

Continuamos nuestro recorrido con Freeman Tilden, que publica en 1957 Interpreting our heritage, la base teórica sobre la que se fundamenta la interpretación del patrimonio, definida por el autor como "una actividad educativa que pretende revelar significados e interrelaciones a través del uso de objetos originales, por un contacto directo con el recurso o por medios ilustrativos, no limitándose a dar una mera información de los hechos" (Tilden 2006). En España, la Asociación de Intérpretes del Patrimonio no se creará hasta 1999.

\section{Comisión Franceschini y Carta de Venecia (1964)}

La teoría de los bienes culturales y la Carta de Venecia (1964) van a suponer la superación de la concepción objetual a partir de la importancia otorgada a la relación y comunicación con el entorno (la ciudad, en el caso de la Carta de Venecia) y los sujetos que lo definen. Este salto de escala será un posicionamiento fundamental para entender el peso de la mediación comuni- 
cativa entre el territorio y las personas que lo habitan, entre el patrimonio y las comunidades que le dan sentido. Es decir, la existencia hoy de redes sociales en las instituciones culturales debe mucho a este cambio de paradigma: dejamos de poner el foco en el objeto y buscamos las interrelaciones, primero analógicas, después también digitales.

\section{Apocalípticos e integrados también en el patrimonio (1965)}

En 1965 publica Umberto Eco Apocalípticos e integrados. La semiótica se suma como una corriente desde la que comprender la realidad patrimonial, dado que el tradicional modelo funcionalista y lineal de comunicación no podía explicar la complejidad del patrimonio y, fundamentalmente, la relación entre los museos y la sociedad. Esta evolución culminará años más tarde con la nueva museología de Rivière, el cuestionamiento de la rigidez de la institución museística, la idea del ecomuseo abierto a la sociedad y, por supuesto, la adopción (ya veremos con qué grado de perspectiva crítica) de las redes sociales como herramientas para abordar esta relación.

\section{La necesidad de informar en la Convención del Pa- trimonio Mundial y el patrimonio como espectáculo (1972)}

Si bien hay otras referencias a la difusión en artículos anteriores (11.4 y 13.5, entre otros) es el artículo 27 el que se centra en la necesidad de informar y estar informados a través de programas de educación e información. Este año se publica también la Carta del restauro de Cesare Brandi y se celebra la primera gran exposición sobre los tesoros de la tumba de Tutankamón. Itinerante desde 1972 a 1979 por Estados Unidos, antigua URSS, Japón, Francia, Canadá y Alemania, alcanza la cifra de 8 millones de visitantes solo en Estados Unidos. Tal y como señala Beatriz Sanjuán en el Estudio de viabilidad y adecuación como generador de usos para las Reales Atarazanas de Sevilla (2008): "este tipo de exposiciones se convierte en hito social, además de cultural. En mito, en paradigma para la futura política expositiva, que, a partir de entonces, deja de atender a la novedad discur-

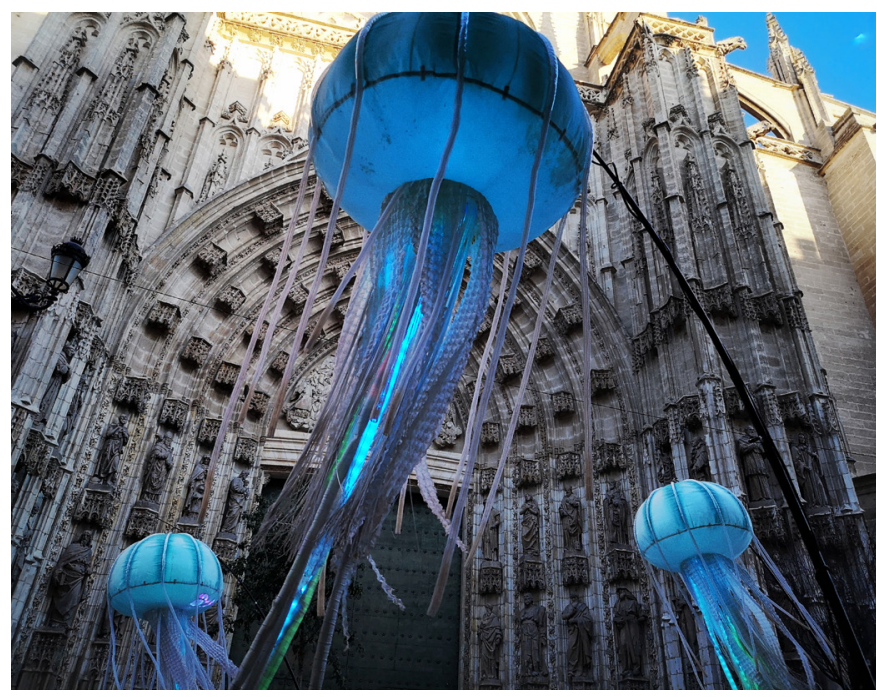

Sociedad líquida | foto Juanma García Nieto

siva para prestar atención sobre la capacidad de cautivar espectadores. Lo cualitativo se sustituye por lo cuantitativo, en el marco de un modelo de exhibición-atención característico de la sociedad comunicativa, posmoderna y global".

\section{La comunicación para el desarrollo (1982)}

La Conferencia Mundial sobre las Políticas Culturales celebrada en México en 1982 inicia los debates sobre uno de los conceptos más tratados hasta la fecha, el desarrollo sostenible y la cultura $-\mathrm{y}$, por tanto, el patrimonio- como motor de desarrollo económico y social. Los artículos 37 y 40 de la declaración se dirigen a los medios de comunicación y su responsabilidad y deber social como facilitadores de información objetiva sobre la cultura y como instituciones fundamentales para la educación y difusión al servicio de las naciones.

\section{La Ley de Museos de Andalucía (1984)}

La finalidad que persigue esta Ley es la ordenación y difusión de un Sistema Andaluz de Museos y la salvaguarda de los fondos museísticos. Destacamos cómo en la exposición de motivos del texto, se incluye la idea de superación del tradicional sentido de museo como espacio para el depósito de obras reservado a la minoría que sabe, para "entenderlo como un núcleo de proyección 
a debate Comunicación y redes sociales en instituciones culturales

| coordina Candela González Sánchez

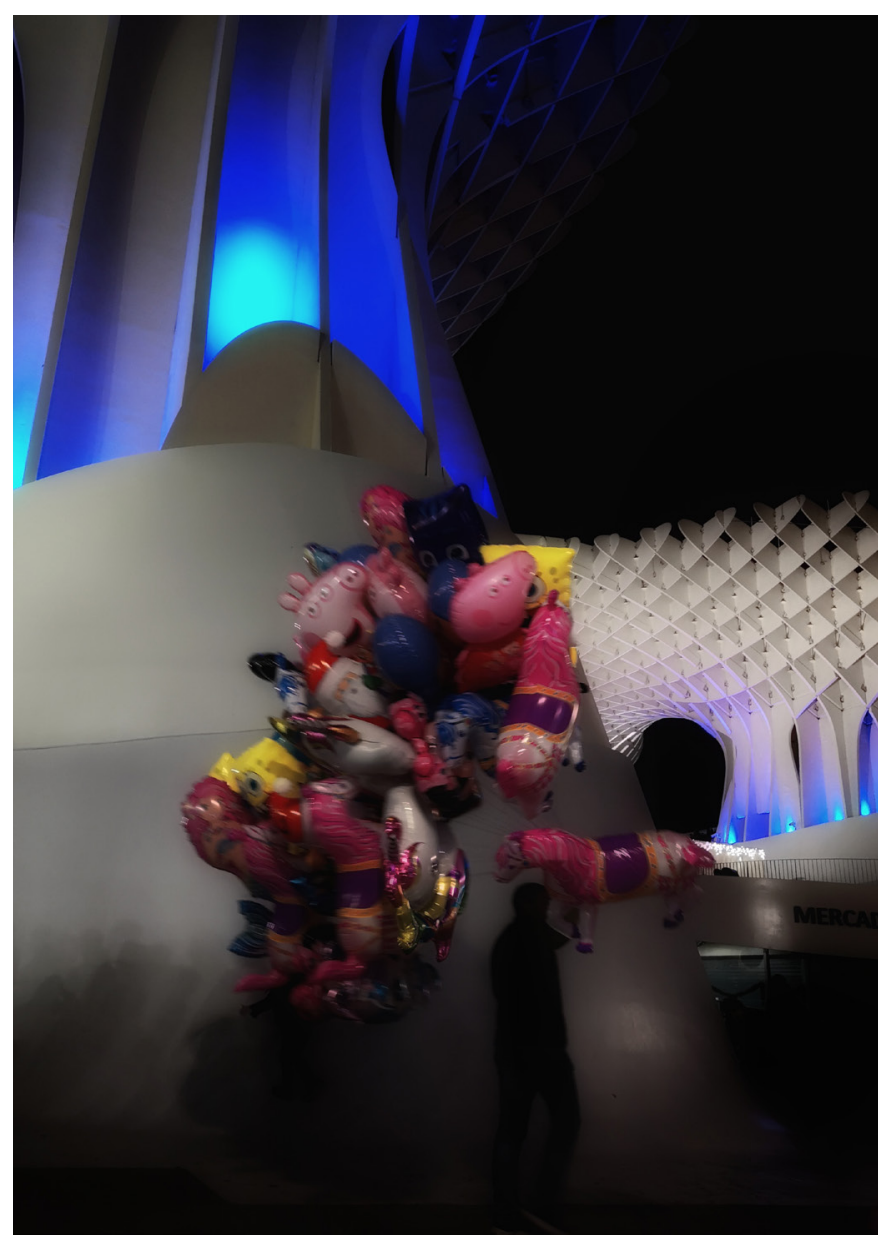

Marketing urbano | foto Juanma García Nieto

cultural y social, con una continua y decisiva función didáctica. En suma, considerarlo como ámbito de múltiples actividades y usos, pero siempre desde la óptica de una aproximación viva a la cultura."

\section{Una estructura para la difusión del patrimonio en el} I PGBBCC (1989)

El I Plan General de Bienes Culturales (1989-1996) dedicaba su capítulo 4 al Programa de Difusión del Patrimonio Histórico que, a su vez, se dividía en tres planes: Plan de Exposiciones, Plan de Publicaciones y Plan de Divulgación del Patrimonio Histórico. Este último, centrado fundamentalmente en la experiencia de los Gabinetes Pedagógicos, si bien cabe destacar cómo entre sus objetivos marca el hito de la creación de departamentos de difusión en la estructura de las instituciones del patrimonio.

\section{La difusión en la primera ley de patrimonio de Andalucía (1991)}

El preámbulo de la Ley $1 / 1991$ de 3 de julio de Patrimonio Histórico de Andalucía concluye que "la presente Ley desarrolla los instrumentos necesarios para la tutela de nuestro Patrimonio Histórico, siendo consciente de que la mejor garantía de su conservación y enriquecimiento será su adecuada difusión". En este sentido, la figura del Catálogo General del Patrimonio Histórico Andaluz va a ser el instrumento protagonista.

\section{Diagnóstico de la comunicación del patrimonio: II} PGBBCC y monografía del IAPH (1996)

El II Plan General de Bienes Culturales (1996) comprende el patrimonio cultural como dinamizador económico y motor de desarrollo. En su Programa de Comunicación, Educación y Participación se reconoce que "la difusión del patrimonio no tiene un desarrollo normativo que obligue a actuar en una dirección $u$ otra, como es el caso de la protección o conservación. Tampoco está clara la procedencia académica e los profesionales que deban ejercerla ni su perfil formativo". Tanto es así, que uno de los objetivos del programa es la profesionalización, dentro de la Dirección General de Bienes Culturales, de las labores de comunicación del patrimonio (crear una estructura, conocer los públicos, utilizar los medios de comunicación, generar información, inventariar el material de difusión y elaborar bases de datos para ampliar la cobertura informativa, eran las medidas necesarias que se citaban entonces). Este año, edita el Instituto Andaluz del Patrimonio Histórico la monografía Difusión del Patrimonio Histórico que supone un esfuerzo por revisar y situar el papel de la difusión del patrimonio.

\section{Comunicar o vender: el marketing urbano (1997)}

"La capacidad del patrimonio cultural para generar símbolos representa hoy una oportunidad cuyo efecto va más allá de lo social y tiene una incidencia clara en otros 
ámbitos, entre ellos, la economía" (Garrote 2011, 9). La inauguración del Museo Guggenheim Bilbao, del arquitecto Frank O. Gehry, constituye un ejemplo claro de la compleja asociación entre cultura, turismo y economía, puesto que una operación urbanística se vincula a una política cultural a través de la necesidad de equipamientos culturales. Podríamos concluir, en este sentido, que han prevalecido las políticas de visibilidad frente a las de territorialidad, donde se diluye la inversión. La competición por conseguir que una de las grandes firmas de la arquitectura deje su impronta en las ciudades se establece como tendencia, está de moda. A partir de este momento, las ciudades emplean la comunicación como herramienta para vender una imagen, un eslogan, tal y como advertimos recorriendo los portales web de los ayuntamientos de las ciudades: "Sevilla, la construcción de un sueño"; "Cádiz, la ciudad que sonríe"; "Barcelona, obert per vacances" (Barcelona, abierta en vacaciones); "Conoce Madrid"; "Bilbao, segi aurrera" (Bilbao, ¡sigue adelante!); etcétera.

\section{La participación en la Carta de Cracovia (2000)}

Y llegamos al año 2000 con el concepto de participación en la Carta de Cracovia, que en su artículo 12, señala: "La pluralidad de valores del patrimonio y la diversidad de intereses requiere una estructura de comunicación que permita, además de a los especialistas y administradores, una participación efectiva de los habitantes en el proceso. Es responsabilidad de las comunidades establecer los métodos y estructuras apropiados para asegurar la participación verdadera de individuos e instituciones en el proceso de decisión.“

\section{Sensibilización sobre el patrimonio inmaterial (2003)} La Convención de París para la Salvaguarda del Patrimonio Cultural Inmaterial (2003) emplea el término de sensibilización vinculado a las acciones de comunicación, especialmente dirigidas a los jóvenes (artículo 14).

\section{El paisaje como objeto de estudio (2005)}

En el marco de apoyo a la aplicación del Convenio Europeo del Paisaje (2000, si bien España lo ratifica en 2008) nace el Observatorio del Paisaje de Cataluña con una marcada línea de trabajo que incluye la comunicación en su aproximación al conocimiento de los paisajes culturales. Los estudios sobre el paisaje van concentrar un gran número de investigaciones desde la comunicación, como es el caso de los trabajos de Joan Nogué y Jordi de San Eugenio Vela (San Eugenio 2006b), de la Universidad de Vic. Ambos han considerado fundamentalmente la semiótica como herramienta de trabajo desde la comunicación, en tanto que los paisajes son signos (lectura semiótica del paisaje). En el ámbito más cercano, los proyectos desarrollados por el Instituto Andaluz del Patrimonio Histórico, a través del Laboratorio del Paisaje Cultural, se van a convertir en referentes para el estudio del paisaje y su difusión.

\section{Binomio patrimonio-comunicación en el PECA (2006)} En 2006 comienza a elaborarse el Plan Estratégico para la Cultura en Andalucía (PECA 2008-2011) que incluía un apartado dedicado al escenario de los medios de comunicación en Andalucía, lo que supone un paso importante al considerarse un elemento definitorio más del territorio en el que se implanta la política cultural. Se diagnostica que la información relativa a los bienes culturales está dispersa, desestructurada, lo que incide negativamente en su gestión. Por otro lado, la protección del patrimonio debe considerar, cada vez más, ámbitos territoriales más amplios, y no elementos aislados y sin relación con el entorno. Todas estas claves arrojan luz sobre la importancia que adquiere el papel de la comunicación como garante de la relación entre la ciudadanía, la administración y el territorio.

\section{PAIDI: comunicación y patrimonio como línea de investigación (2007)}

Tal y como se recoge en el texto del Plan Andaluz de Investigación, Desarrollo e Innovación (PAIDI 20072013), las líneas directoras de la actividad investigadora en Andalucía no pueden anclarse en los sectores tradicionalmente estratégicos, sino que deben contemplar otros campos hasta ahora sin explotar, pero capaces de aportar nuevos conocimientos y de abrir nuevas líneas de acción del máximo interés para la comunidad científica y la sociedad en general. El programa sectorial de 
a debate Comunicación y redes sociales en instituciones culturales

| coordina Candela González Sánchez

investigación en Cultura considera como una de sus líneas estratégicas la investigación en comunicación e interpretación para establecer puentes de relación entre el patrimonio y la sociedad.

\section{El primer estudio de público en España sobre patrimonio (2008)}

Afirma Gabriel Morate (2007) que, "pese a la importancia que tiene esta dimensión subjetiva y democrática del patrimonio histórico, carecemos de estudios científicos y globales que nos permitan valorarla más allá de nuestra intuición y nuestra experiencia". Es por ello que durante los años 2006-2008, el Programa de Conservación del Patrimonio Histórico Español de la Fundación Caja Madrid, a través de la empresa Euro Netresearch, llevó a cabo un estudio sobre el conocimiento y percepción del patrimonio en la sociedad española. La investigación, con una primera fase cualitativa de aproximación a los conceptos que la sociedad maneja sobre el patrimonio y una segunda fase cuantitativa, concluía que existía cierta inconsistencia en el discurso sobre lo patrimonial, que seguía vinculado a los monumentos antiguos más conocidos y una valoración del patrimonio, pese al desconocimiento generalizado.

\section{El Instituto Andaluz del Patrimonio Histórico abre sus perfiles en redes sociales (2009)}

Por aquel entonces, yo estaba acabando una beca de investigación en patrimonio y comunicación en la institución, y recuerdo la apuesta decidida, pero también los miedos subyacentes. No existían apenas referentes estatales y muchas de las personas que andábamos dándole vueltas entonces a eso de las redes, la comunicación y el patrimonio, nos juntamos para compartir ilusiones e incertidumbres en el seminario organizado por el entonces Instituto Valenciano de Conservación y Restauración (IVC+R) ${ }^{2}$, Restauramos, investigamos y lo contamos. Recursos y posibilidades de las Tecnologías de la Información y Comunicación. Mucho ha llovido desde entonces, aparecieron bajo el paraguas de FECYT las Unidades de Cultura Científica y de la Innovación (UCC+i) para divulgar la ciencia del patrimonio, el patrimonio inmaterial puso en el centro a las personas, pero ¿cuáles son las lecciones aprendidas en materia comunicación y patrimonio?

\section{Lecciones aprendidas en una década (2010-2020)}

La primera de ellas tiene que ver con algo que señalaban ya en 2007 autores como Florencio Cabello y Beatriz Sanjuán, a partir de las tesis de Jesús Martín Barbero (1993) sobre mediaciones. "Coincidente con una revalorización del sujeto destinatario y del acto de consumo o recepción dentro del proceso de comunicación, surge una nueva manera de comprender la ligazón mediática, las 'mediaciones' que permiten imbricar lo social con unas industrias culturales en plena expansión. Estamos, en efecto, ante un enfoque más humano y social, más complejo y, sobre todo, radicalmente cultural". Situarnos en las mediaciones supone, continúa Cabello, "superar la empobrecedora centralidad de los medios y dar cabida a la multiplicidad de factores sociales que conforman las prácticas de consumo" (Cabello Fernández-Delgado 2007).

Situarse en este paradigma alternativo, que arranca con los estudios culturales de la Escuela de Birmingham y pasa por las mediaciones desde el ámbito latinoamericano, nos lleva a cuestionar, ineludiblemente, los análisis centrados en la difusión o transmisión de información, también en el caso que nos ocupa, en el impacto y triunfalismo de las redes sociales. Comentaba al respecto de la "revolución digital" el catedrático de Teoría de la Comunicación de la Universidad de Sevilla, Francisco Sierra: "La cuestión es, con estas transformaciones, qué tipo de sociedad emerge y qué tipo de rupturas o quiebres culturales"3. Vamos a visibilizar estas rupturas a partir de algunas aportaciones recibidas en el debate y que puedes completar con los textos que siguen al presente artículo.

En El uso de las redes sociales: algunos ejemplos tomados de museos de Castilla y León, Antonio Bellido denomina a las redes "puertas digitales que están abiertas para todos y se han creado nuevos canales de difusión para estas instituciones". Cabe preguntarse, al mismo tiempo, sobre el mito del acceso universal a una tecno- 


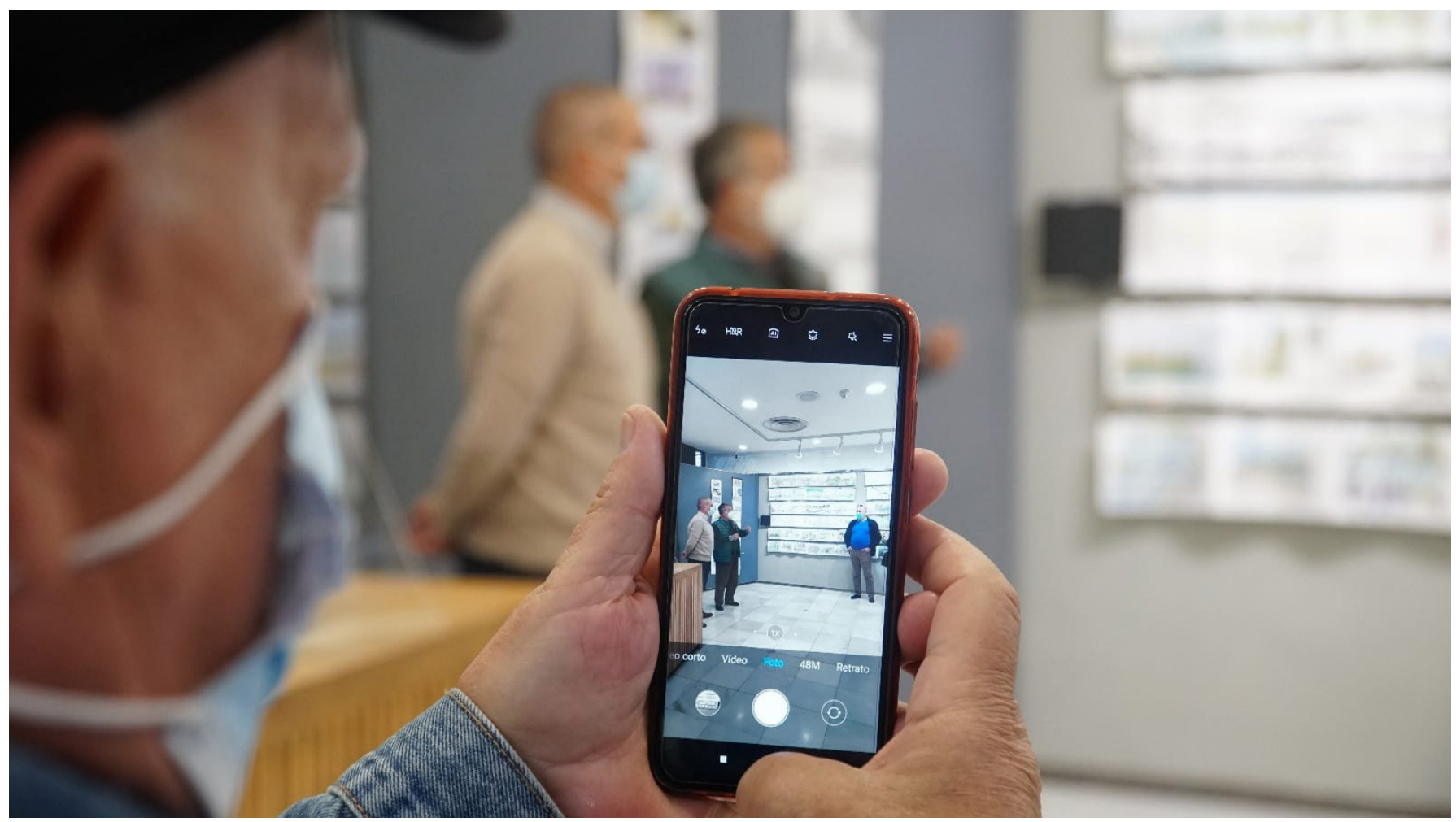

Brechas digitales | foto Candela González Sánchez

logía producida por el norte, con materias primas del sur, una brecha digital que nos habla de ruralidad, género, edad, educación y, en definitiva, que nos evidencia asimetrías.

El enfoque arqueológico desde el que nos invitan a mirar Michelle y Armand Mattelart ${ }^{4}$ nos habla de la pervivencia de algunos mitos que ocultan algunos aspectos del avance tecnológico: el mito de la transparencia, del progreso, de la universalidad, de la paz y de la normalización cultural. A esto se suma, como señala Jaime Almansa, en Veinte frenéticos años de arqueología en la red y una pandemia para unirlos a todos, el mito de la democratización de internet al tiempo que se produce la dictadura del algoritmo, apostando por un acercamiento crítico al potencial de las redes y la necesidad de cuestionar los modelos. Nos habla de las comunidades online y se pregunta si no se siguen reproduciendo los esquemas de lo presencial e innovando poco. Una defensa de la presencialidad propugna también L. Alberto Polo, en su texto Redes sociales y arqueología en la España vaciada: Proyecto Arqueosequera, y en esta misma línea se sitúan Jaime Vergara y Miguel Martínez, en Arquitectura, fotografía y redes sociales, cuando nos advierten de algunos riesgos: "Lo más inmediato, que ya se atisba, es que las imágenes reemplazan la experiencia directa del espacio construido. Pero existen otros peligros que se pueden cifrar: en primer lugar que el consumidor de esa arquitectura visual acabe con dificultades para asimilar la capacidad de las fotografías para transportarnos a momentos y lugares específicos, independientemente de la distancia; en segundo lugar que el 'ruido' de las imágenes sea tan constante que se pierda la serenidad y sensibilidad por lo real; y en tercer lugar que el gusto por la arquitectura se sacie de imágenes perfectas, alteradas por filtros de luz y ediciones digitales que nos distancian de la belleza natural de la obra imperfecta". 
a debate Comunicación y redes sociales en instituciones culturales

| coordina Candela González Sánchez

Cecilia Casas y Demian Ramos, en su contribución El Museo Cerralbo explora vías de comunicación novedosas durante 2020, hablan de la "rigidez de los perfiles institucionales" (el lenguaje que utilizan, sus formas a veces distantes, los temas que tratan, la frecuente confusión entre rigurosidad y exceso de academicismo, o en la distancia que marcan en sus conversaciones respecto a sus seguidores y seguidoras, etc.), "poco amigas de la bidireccionalidad y acostumbradas a un discurso incontestable".

En esta misma línea apunta Lourdes Páez, en su texto Cultura abierta sin horario ni calendario. El museo de las redes sociales, cuando pone el foco en el cambio de mentalidad en las instituciones, acostumbradas al monólogo o discurso incontestable, que cada vez más salta por los aires con las redes sociales. Habla también de la creación de comunidad, donde los sentimientos afloran: enfado, decepción, ilusión... En este sentido resulta muy interesante la aportación que hace Sara Guasteví, en Las redes sociales: Ios 7-eleven de los museos, que nos habla de la necesaria búsqueda de complicidades, reforzando el sentido de pertenencia, los vínculos, si se quiere lograr una comunidad. Y, en ella, distintas realidades, como apunta Stella Maldonado, en su texto Las redes sociales, espacios de generación de energía cultu-

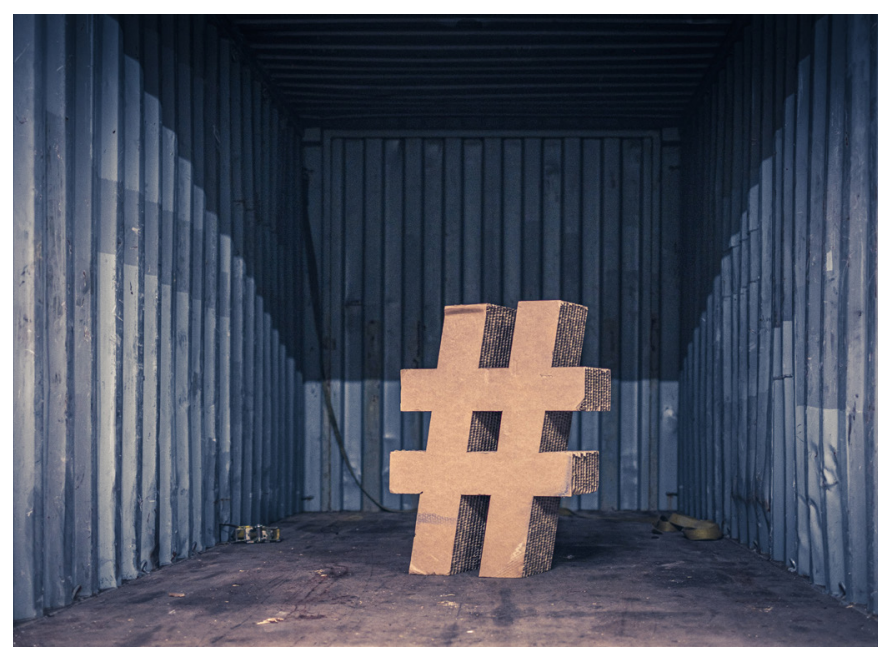

Hashtag | foto Jan Baborák ral: "dentro de la gran comunidad cultural digital también hay lugar para lo micro, lo pequeño. Han ido surgiendo comunidades de identidad, de aprendizaje, de relación, que van tejiendo el verdadero sentido de lo digital: compartir y crear". En palabras de Rocío del Pozo y Laura Fernández, "enriquecer las formas de mirar, sumar y unir."

Parece haber consenso en la idea de profesionalizar la gestión de las redes, en varias de las aportaciones. Así nos lo cuentan, por ejemplo, Sandra Sancho, Claudia Alfonso y Olga Palomares, en Cultura y redes sociales. Una ventana infinita que necesita profesionalidad. Iñaki Navarro, en Estrategias educomunicativas de los museos arqueológicos y de sitio españoles durante el estado de alarma, se refiere también a esta cuestión de los perfiles: "cuentas oficiales gestionadas mayoritariamente por personal itinerante, sin formación específica en redes y cuya continuidad a la hora de publicar dependía de la voluntad y destreza del propio personal del museo sin una política o estrategia definida". Carmen Sánchez, por su parte, en Las redes sociales y la transformación de las instituciones, nos habla de contradicciones y de la necesidad de que la estrategia de incursión en redes se acompañe de una estrategia general de redes en la institución, señal de que se cree en el proyecto, y de que las instituciones pierdan el miedo a comunicarse con el exterior y a incorporar las expectativas del público. $Y$ es que, celebramos que hemos alcanzado miles de seguidoras/es y que contamos con un presupuesto para promocionar en redes, pero en el seno de muchas instituciones seguimos debatiendo si ese comentario crítico debe dejarse o eliminarse.

Señalaba Cristina Gómez en Twitter cultural contra cuentas institucionales. Nuevos modos de divulgación cultural que "las cuentas han de ser completamente ajenas a los vaivenes políticos", y por eso nos preguntábamos al inicio del debate ¿en qué anda el tejido cultural no institucional enredado?, porque quizás podamos encontrar mayores cuotas de creatividad, libertad, autonomía e innovación, fuera del corsé del museo, paradigma de la institución cultural. 


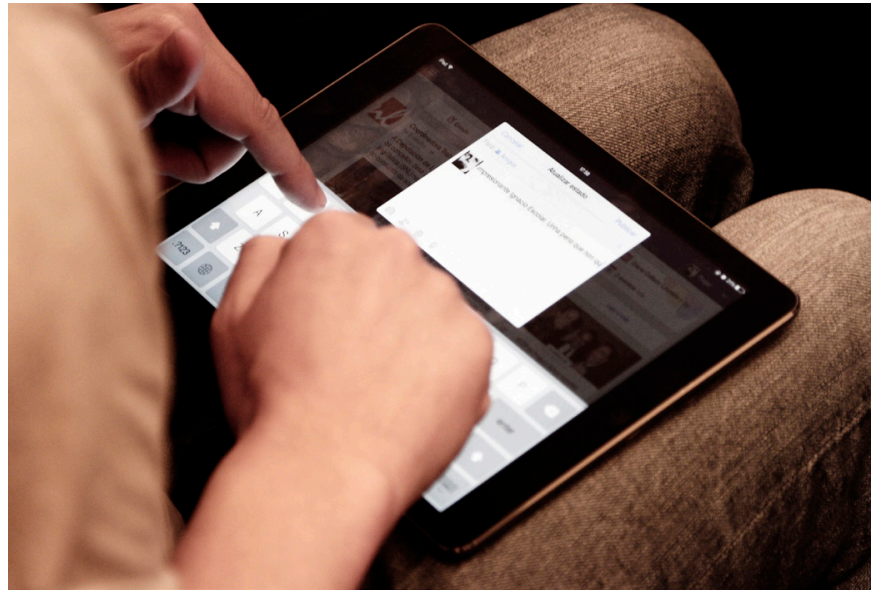

III Congreso cultura digital y redes sociales

Leonor Amaral, en su texto Los museos durante la pandemia: el importante papel de las redes cociales, retoma la idea de las asimetrías, en este caso, en relación con los recursos que se necesitan para estar en constante actualización, "Porque cuando un museo invierte en la adquisición de equipamiento tecnológico debe saber que este no solo requiere costes de mantenimiento, sino que además terminará desactualizado, probablemente, en un espacio de dos o tres años. (...) Sin embargo, este también ha sido un período en el que se han puesto de manifiesto los desequilibrios en la inversión y los recursos enfocados a la acción digital, y se ha hecho una importante reflexión sobre la presencia en Internet de cada institución museística". Layre Salgado, Nuria López y Samuel González destacan que las redes nos han permitido comunicar al ritmo frenético de los acontecimientos durante la pandemia que estamos viviendo, a una velocidad que otros canales no permitían.

El tiempo es una variable demasiado importante cuando hablamos de medios de comunicación y de redes sociales, y no solo por el ritmo de renovación de una tecnología que queda obsoleta demasiado rápido, o por la exigencia de la inmediatez, sino también por los tiempos de consumo que han cambiado nuestros hábitos hasta llegar, en demasiadas ocasiones, a relaciones adictivas con estas herramientas. Y es que las redes son rápidas, eso es seguro. Habrá que ver también qué pasa con esos otros procesos de digestión más lenta, la lectura comprensiva y no diagonal, lo textual y no solo audiovisual, la reflexión, el análisis. Para la comunicación del patrimonio, también, tomémonos el tiempo.

\section{NOTAS}

1. Si tomamos como referencia el nacimiento de Sixdegrees en 1997, para el resto, tendremos que esperar algunos años más. Así, Facebook nace en 2004, Youtube en 2005, Twitter en 2006, WhatsApp aparece en 2009 e Instagram en 2010, por citar solo algunas.

2. Desde 2013, Subdirección de Conservación, Restauración e Investigación IVC+R de CulturArts Generalitat.

3. Entrevista íntegra realizada por El Salto (30 de octubre de 2020) en https://www.elsaltodiario.com/comunicacion/marxismo-y-comunicacion-entrevista-francisco-sierra-caballero

4. Por citar solo algunas de sus obras: Mattelart, Armand y Michèle (2005) Historia de las teorías de la comunicación. Bacelona: Paidós Comunicación; Mattelart, Armand y Michèle (1987) Pensar sobre los medios. Comunicación y crítica social. Madrid: Fundesco; Mattelart, Armand (1993) La comunicación-mundo. Historia de las ideas y las estrategias. Madrid: Fundesco; Mattelart, Armand (1995) La invención de la comunicación. Barcelona: Editorial Bosch; Mattelart, Armand y Michèle (1997) Historia de las teorías de la comunicación. Barcelona: Paidós.

\section{BIBLIOGRAFÍA}

- Ardemagni, M. (2007) Patrimonio y público. La labor de sensibilización a través de los medios de comunicación. En: Sanjuán Ballano, B (coord.) Patrimonio cultural y medios de comunicación. Sevilla: Instituto Andaluz del Patrimonio Histórico, Consejería de Cultura, Junta de Andalucía, 2007, pp. 70-79

- Castillo, C. del (2020) Raúl Magallón: "Las redes sociales ya no son solo empresas tecnológicas sino actores políticos". 


\section{a debate Comunicación y redes sociales en instituciones culturales}

| coordina Candela González Sánchez

elDiario.es, 15 de octubre de 2020. Disponible en: https://www. eldiario.es/tecnologia/raul-magallon-redes-sociales-no-sonempresas-tecnologicas-actores-politicos_128_6295992.html [Consulta: 05/11/2020]

- Cabello Fernández-Delgado, F. (2007) Industrias culturales y procesos de lectura. Puntos de partida para abordar la comunicación desde el patrimonio. En: Sanjuán Ballano, B (coord.) Patrimonio cultural y medios de comunicación. Sevilla: Instituto Andaluz del Patrimonio Histórico, Consejería de Cultura, Junta de Andalucía, pp. 12-29

- Consejería de Cultura (2007) PECA. Plan Estratégico para la Cultura en Andalucía (2008-2011) Consejería de Cultura, Junta de Andalucía

- Eco, U. (1996) Apocalípticos e integrados. Barcelona: Lumen

- García Canclini, N. (1990) Culturas híbridas. Estrategias para entrar y salir de la modernidad. México: Grijalbo

- García-García, A. (coord.) (2008) Espacio público, ciudad y conjuntos históricos. Sevilla: Instituto Andaluz del Patrimonio Histórico, Consejería de Cultura, Junta de Andalucía, 2008 (PH Cuadernos 22)

- Garrote, L. (coord.) (2011) El patrimonio cultural como símbolo. Actas del Simposio Internacional. Valladolid: Fundación del Patrimonio Histórico de Castilla y León

- Grijota, E. (2020) Adiós academia, hola TikTok: la estrategia sin complejos con la que la Galería Uffizi ha duplicado los visitantes jóvenes en tres meses. El País, 19 de octubre de 2020. Disponible en: https://elpais.com/icon-design/2020-10-18/ adios-academia-hola-tiktok-la-estrategia-sin-complejos-conla-que-la-galeria-uffizi-ha-duplicado-los-visitantes-jovenes-entres-meses.html [Consulta: 05/11/2020]

- IAPH (1997) Difusión del Patrimonio Histórico. Sevilla: Instituto Andaluz del Patrimonio Histórico, Consejería de Cultura, Junta de Andalucía, 1997 (PH Cuadernos)

- IAPH (2008) Estudio de viabilidad y adecuación como generador de usos para las Reales Atarazanas de Sevilla. Sevilla: Instituto Andaluz del Patrimonio Histórico

- Martín Guglielmino, M. (2007) La difusión del patrimonio. Actualización y debate. erph_revista electrónica de patrimonio histórico, n. ${ }^{0}$ 1. Disponible en: https://revistadepatrimonio.es/ index.php/erph/article/view/23/7 [Consulta: 05/11/2020]

- Martín-Barbero, J. (1993) De los medios a las mediaciones. Cultura, hegemonía y poder. México: Gustavo Gili

- Mattelart, A. y Mattelart, M. (2005) Historia de las teorías de la comunicación. Barcelona: Paidós Comunicación

- Mattelart, A. y Mattelart, M. (1987) Pensar sobre los medios. Comunicación y crítica social. Madrid: Fundesco

- Mattelart, A. (1993) La comunicación-mundo. Historia de las ideas y las estrategias. Madrid: Fundesco
- Mattelart, A. (1995) La invención de la comunicación. Barcelona. Editorial Bosch

- Mattelart, A. y Mattelart, M. (1997) Historia de las teorías de la comunicación. Barcelona: Paidós

- Ministerio de Culturay Deporte (2020) ¿Cómo comunicamos? Las redes sociales y los museos a debate. I Encuentro Día Internacional de las Redes Sociales. Disponible en: http:// www.man.es/man/actividades/actividades-extraordinarias/ historico-extraordinarias/2020/20200630-dia-internacionalredes-sociales.html [Consulta: 02/02/2021]

- Ministerio de Cultura y Deporte (2020) Encuentro virtual: ¿Cómo comunicamos? las redes sociales y los museos a debate. II Encuentro Día Internacional de las Redes Sociales Disponible en: https://www.culturaydeporte.gob.es/mgreco/ actividades/conferencias/encuentrovirtual.html [Consulta: 02/02/2021]

- Morate Martín, G. (2007) Conocimiento y percepción del patrimonio histórico en la sociedad española. erph_revista electrónica de patrimonio histórico, n. ${ }^{\circ} 1$ Disponible en: https://revistadepatrimonio.es/index.php/erph/article/view/24 [Consulta: 30/01/2021]

\section{- Orlowski, J. (2020) The Social Dilemma. Exposure Labs}

- Peña Aznar (De la) (2014) ¿Sirven para algo las redes sociales en el sector cultural? En: Anuario AC/E de cultura digital. Acción cultural española, pp. 101-112. Disponible en: https:// www.accioncultural.es/media/Default\%20Files/activ/2014/Adj/ Anuario_ACE_2014/8RedesSociales_JPen\%CC\%83a.pdf [Consulta: 05/11/2020]

- Quintero, V. (2009) Los sentidos del patrimonio. Alianzas y conflictos en la construcción del patrimonio etnológico andaluz. Sevilla: Fundación Blas Infante

- Rizo, M. y San Eugenio, J. (2007) Aportacions de la Teoria de la Comunicació a l'estudi transversal del paisatge. Proposta d'indicadors. En: Nogué, J., Puigbert, L. y Bretcha, G. (ed.) Indicadors de paisatge. Reptes $i$ perspectives. Olot: Observatorio del Paisaje de Cataluña; Barcelona: Obra Social de Caixa Catalunya, pp. 300-320. Disponible en: http://www. catpaisatge.net/fitxers/publicacions/indicadors/14_Marta Rizo_Jordi_deSan_Eugenio.pdf [Consulta: 05/11/2020]

- Rosenstein, J. (2020) Las redes sociales, amenaza para la democracia. El País, 27 de octubre de 2020. Disponible en: https://elpais.com/opinion/2020-10-26/una-amenaza-para-lademocracia.html [Consulta: 05/11/2020]

- San Eugenio, J. (2006a) La interpretación del paisaje como instrumento de comunicación con la sociedad. Aportaciones de la semiótica y de los procesos de participación ciudadana. Revista F@ro, monográfico, n. ${ }^{\circ}$ 4, año 2. Disponible en: http://web.upla.cl/revistafaro/02 monografico/04 jordi.htm [Consulta: 02/02/2021]

- San Eugenio, J. (2006b) Propuestas para una aproximación 
al estudio comunicacional del paisaje. Comunicación presentada en el marco del IV Encuentro Brasil-España de Ciencias de la Comunicación. Málaga, 24-26 de abril de 2006

- Sanjuán Ballano, B. (coord.) (2007) Patrimonio cultural y medios de comunicación. Sevilla: Instituto Andaluz del Patrimonio Histórico, Consejería de Cultura, Junta de Andalucía (PH Cuadernos 21)

- Sanjuán Ballano, B. (2007) Información = Cultura. Mapas patrimoniales para ir de los medios a las mediaciones. En: Sanjuán Ballano, B. (coord.) Patrimonio cultural y medios de comunicación. Sevilla: Instituto Andaluz del Patrimonio Histórico, Consejería de Cultura, Junta de Andalucía, pp. 3044 (PH Cuadernos 21)

- Sierra, F. (1999) Elementos de Teoría de la Información. Sevilla: Editorial MAD

- Tilden, F. (2006) La interpretación de nuestro patrimonio (Primera edición en castellano). Sevilla: Asociación para la interpretación del patrimonio

- Watsuji, T. (2006) Antropología del paisaje. Salamanca:

Ediciones Sígueme 